\title{
Constipated Patients Fed Goat Milk Protein Formula: A Case Series Study
}

\author{
Infante $\mathrm{DD}^{*}$, Prosser $\mathrm{CG}^{2}$, and Tormo $\mathrm{R}^{3}$
}

\author{
${ }^{1}$ Unit of Gastroenterology and Nutrition, General Hospital of Catalonia, Sant Cugat del Vallès (Barcelona), Spain \\ ${ }^{2}$ Dairy Goat Co-operative (NZ) Ltd, Hamilton, New Zealand \\ ${ }^{3}$ Chiron Clinic, Barcelona, Spain
}

${ }^{*}$ Corresponding author: Infante DD, Unit of Gastroenterology and Nutrition, General Hospital of Catalonia, Sant Cugat del Vallès (Barcelona), Spain, E-mail: damasoinfante@gmail.com

Citation: Infante DD, Prosser CG, Tormo R (2018) Constipated patients fed goat milk protein formula: A case series study. J Nutr Health Sci 5(2): 203. doi: 10.15744/2393-9060.5.203

Received Date: March 06, 2018 Accepted Date: April 20, 2018 Published Date: April 24, 2018

\begin{abstract}
Aim: To observe the impact of an infant formula containing goat milk proteins and fat in infants exhibiting symptoms of constipation.

Methods: This study employed a case-series design with infants aged between 1 and 4 months. Infants with symptoms of constipation were recruited at two paediatric clinics in Barcelona, Spain. At the time of recruitment, all infants were fed a standard formula made with cow milk protein. Infants were provided with a formula based on goat milk protein and 55\% of total fat from goat milk. After 3 weeks, stool consistency, stool frequency, crying and infant behaviour were measured. Fat, nitrogen, water and carbohydrates in the stools were also determined by NIRA (near-infrared reflectance analysis).

Results: A total of 23 infants were enrolled and 20 completed the study. Two infants withdrew due to causes considered unrelated to formula and one due to persistent irritability. Fat percentage of stools declined from 8.6 to $6.8 \mathrm{~g} / 100 \mathrm{~g}(\mathrm{P}<0.001)$ and crying from 3 to $1 \mathrm{~h} / 24 \mathrm{~h}(\mathrm{P}<0.001)$ after three weeks compared to enrolment. Crying immediately after feeding was more common in infants at enrolment compared to the second visit, $75 \%$ vs $25 \%$ respectively. Parents reported change in infant behavior 3-5 days after the study formula was introduced. The mean consistency score of the stools was significantly $(\mathrm{P}<0.05)$ lower (harder) at enrolment than at the second visit. Stool frequency did not change.
\end{abstract}

Conclusion: The improvement of stool characteristics and reduction in crying in infants indicates that formula with proteins and fat from goat milk in infants does not adversely affect gastro-intestinal comfort.

Keywords: Formula; Infants; Goat Milk; Constipation; Stools

\section{Introduction}

Parents pay close attention to the frequency and characteristics of their children's defecation, especially during the first months of life [1-3]. Any deviation from what is perceived to be normal may trigger paediatric consultation. In an observational study of formula fed infants, the prevalence of constipation in infants presenting to paediatric clinics was 7.8-22\% [4,5]. Constipation is classified as a change in frequency, size, consistency of stools or difficulty in defecating [6]. Fewer bowel movements and/or hard stools may result in distension of the colon, pain, irritability and crying in the infant $[7,8]$. A greater median number of stools has been associated with crying in infants in the first 2 months of life compared to those who cried less often [2]. Excessive crying in infants with gastrointestinal disturbances can also have a negative impact on family dynamics due to disrupted sleep and family routines as well as increased parental anxiety, stress and frustration [9-11]. Therefore, it is important that formula is shown not to have any adverse impact on gastro-intestinal function in young infants.

Breast-fed infants have significantly more stools per day than formula-fed ones and only a few (1.1\%) have hard stools compared with $9.2 \%$ of formula-fed infants $[1,3,12]$. There are instances where some formulas can lead to harder and less frequent stools in the infant than others. For example infants fed formulas containing more palmitate from palm olein had less calcium absorption, more insoluble calcium soaps in stools and harder stools than when formula without palm oil is used [13-15].

Goat milk was approved as a source of milk for infant formula in Europe following consideration of the scientific evidence of the essential composition of goat milk based infant and follow-on formulae and data from double blinded randomized control trials $[16,17]$. The assessed formula contained protein and also fat from goat milk to provide saturated fatty acids such as palmitic acid $[17,18]$. While double blinded control trials provided strong evidence of the nutritional adequacy of this formula for healthy infants, there is little data concerning the behavior of infants suffering from functional gastrointestinal disturbances when provided 
this formula under clinical settings [16,17].

A case series study was therefore designed to record the response to infant formula containing goat milk fat in infants exhibiting symptoms of constipation. The outcomes measured were stool fat content and consistency, episodes of crying, formula acceptance and parental satisfaction with the product.

\section{Cases and Methods}

\section{Recruitment of Patients}

This open study was conducted at two paediatric clinics at Hospital General de Catalunya, Sant Cugat del Vallès and Clínica Quirón in Barcelona, Spain in 2016-2017. The trial employed a case-series design with infants aged between 1 and 4 months when presenting with symptoms of constipation. Symptoms included difficulty in elimination of hard stools and at least one of the following characteristics: excessive crying/irritability, painful defecation, difficult passage or the need for external help to defecate [19]. Infants were included if they had no history of neonatal disease, were from healthy mothers and had a normal birth weight. At the time of the consultation, all infants were fed a standard formula made with cow milk protein.

Approval of the study protocol was provided by Department of Pediatrics, Hospital General de Catalunya. Sant Cugat del Vallès (Barcelona). Written informed consent for participation in the study was also obtained from parents.

\section{Procedure}

After enrolment, infants were fed with a formula based on goat milk protein and fat that is commercially available in Europe under the brand name of Capricare-1 (Dairy Goat Co-operative (NZ) Ltd, Hamilton, New Zealand). The composition of the formula is provided in table 1 . This is the same formula evaluated by EFSA and used in several clinical studies [16,17]. According to the manufacturer, the formula is made with goat milk and is supplemented with lactose, vitamins and minerals and essential fatty acids to meet requirements. The formula contains $55 \%$ of total fat from goat milk fat and $45 \%$ from a mixture of unmodified high oleic sun-flower, canola, and sunflower oils in a ratio of 44:30:26. Concentrations of main fatty acids is shown in (Table1). The infants did not receive any other formula or supplement other than the study formula during the observation period.

\begin{tabular}{|c|c|c|}
\hline \multirow{2}{*}{$\begin{array}{c}\text { Nutrient } \\
\text { Energy }\end{array}$} & \multicolumn{2}{|c|}{ Unit Per $100 \mathrm{~mL}$ prepared feed } \\
\hline & $\mathrm{kJ}$ & 280 \\
\hline & kcal & 66 \\
\hline Protein & $\mathrm{g}$ & 1.3 \\
\hline Carbohydrate (lactose) & $\mathrm{g}$ & 7.4 \\
\hline Fat & $\mathrm{g}$ & 3.4 \\
\hline C8:0 Caprylic & g & 0.06 \\
\hline C10:0 Capric & g & 0.17 \\
\hline C12:0 Lauric & g & 0.08 \\
\hline C14:0 Myristic & $\mathrm{g}$ & 0.18 \\
\hline C16:0 Palmitic & g & 0.55 \\
\hline C18:0 Stearic & g & 0.23 \\
\hline C18:1 Oleic & g & 1.58 \\
\hline C18:2 Linoleic acid & g & 0.39 \\
\hline C18:3 $\alpha$-Linolenic acid & g & 0.058 \\
\hline $\begin{array}{c}\% \mathrm{C} 16: 0 \text { in sn-2 posi- } \\
\text { tion }\end{array}$ & & 31 \\
\hline Calcium & $\mathrm{mg}$ & 65 \\
\hline Iron & $\mathrm{mg}$ & 0.71 \\
\hline
\end{tabular}

Table 1: Composition of study formula

\section{Evaluation}

The evaluation was designed using assessments that can be normally applied in clinics. This included a questionnaire about the number of stools per day, episodes of crying, restlessness or complaints during $24 \mathrm{~h}$ and stool consistency. These information was recorded by the parents at inclusion and after 3 weeks of using the study formula. To evaluate stool consistency, the photographic Bristol stool form scale was used [20]. In this scale, 1-2 corresponds to hard stools; 3-4 is intermediate or mushy, 5 is soft and 7 completely liquid. The pediatrician made contact with the parents by telephone after 14 days to check on progress. The satisfaction of the parents with the study formula was assessed by means of a Likert-type scale with possible answers from very satisfied to very dissatisfied. 
A stool sample was taken from each infant at inclusion and after 3 weeks of feeding with Capricare-1. Fat, nitrogen, water and carbohydrates in the stools were determined by NIRA (near-infrared reflectance analysis). The NIRA technique is based on measuring radiation in the near-infrared spectrum (FENIR 8820 infrared analyser, Perten, Hamburg, Germany) on the surface of the sample, i.e., the matrix/substrate ratio, and the infrared reflection on the faecal surface at a given wavelength. The components measured belong to certain functional groups $(\mathrm{CH}, \mathrm{NH}, \mathrm{OH})$ with specific absorption bands in the near-infrared spectrum (700$2500 \mathrm{~nm}$ ). The spectroscopic response (reflection) of a faecal sample is thus related to the concentration of the components (functional groups). The correlation of the reflection taken at 12 wavelengths is determined using a computerized algorithm. Prior to the current study, NIRA measurements of stool fat, nitrogen, water and carbohydrate content in eighty stool samples from infants and children were compared to the same measurements performed using traditional methods [21-24]. Our own results for stool composition, which are comparable to results from other authors, expressed as $\mathrm{g} / 100 \mathrm{~g}$ of stools are: fat: $<5$, nitrogen: $<1.8$, carbohydrates: $<2$ and water: between 80 and 85 . However, the fat content of formula fed infants is usually higher during the first 6 months of life (between 7 and $11 \mathrm{~g} / 100 \mathrm{~g}$ ) [25,26].

\section{Statistical Analysis}

The non-parametric Wilcoxon sign rank test was used to test the statistical significance of differences in stool frequency, consistency and biochemical composition as well as crying episodes between enrollment and the second visit. The level of significance was set at 0.05 . Descriptive statistics such as mean and $95 \%$ confidence interval was calculated for all other observations.

\section{Results}

A total of 23 infants were enrolled and 20 completed the study. One was withdrawn due to a Rotaviral infection unrelated to formula feeding. Another had low weight gain of unknown causes and a third started the study, but then switched to a hydrolysed formula due to continued symptoms of irritability. The baseline characteristics of the 20 infants that completed the study is provided in Table 2. No organic cause of constipation was found at the time of initial consultation. None of the infants had IgE mediated allergy to milk. None of the infants had been given any treatment for the constipation such as an infant formula with oligosaccharides or hydrolysates or laxatives prior to the study or during the study. By chance, twice as many female infants were enrolled as males. All infants were within the -10 to 10 th percentile range for weight. None of the mothers smoked or took drugs or alcohol during pregnancy. None of the mothers presented with complications during pregnancy.

\begin{tabular}{|c|c|c|}
\hline Age at enrolment (days) & 58 & $(38)$ \\
\hline Gestational age (weeks) & 40 & $(0.5)$ \\
\hline Weight at birth (kg) & \multicolumn{2}{|c|}{$3.3(0.3)$} \\
\hline Weight at enrolment (kg) & \multicolumn{2}{|c|}{$4.7(0.9)$} \\
\hline Gender (\% female) & 70 & \\
\hline
\end{tabular}

The mean consistency score of the stools was significantly lower (harder) at enrolment than at the second visit (Table 3). Stool consistency scores for all infants at enrolment were within the 1-3 range, whereas at the second visit they were 3-5.

\begin{tabular}{|c|c|c|c|}
\hline & Visit 1 & Visit 2 & p value $^{*}$ \\
\hline $\begin{array}{c}\text { Stool } \\
\text { consistency } \\
\text { No. Stools / day } \\
\text { Crying hours } \\
\text { 24h }\end{array}$ & 2 & 3 & $<0.05$ \\
*Wilcoxian signed rank test & 2 & $>0.2$ \\
& 2 & 1 & $<0.001$ \\
statistics \\
Table 3: Parental assessments at inclusion and follow-up
\end{tabular}

Infants passed 1 to 2 stools per 24 h over the duration of study. The average number of stools in one day did not differ significantly between the start and end of the study (Table 3).

All infants were reported to show symptoms of restlessness or crying for $1-3 \mathrm{~h} / 24 \mathrm{~h}$ at enrolment, compared to $75 \%$ at the second visit. The total duration of crying was significantly reduced at the second compared to the first visit (Table 3). Crying immediately after feeding was more common in infants at the first visit compared to the second visit, $75 \%$ vs $25 \%$ respectively.

All parents reported an increase in satisfaction with the formula based on Likert-type scale (Table 4). The average duration from when the formula was introduced before any change in symptoms or behaviour was noticed by parents was 4 days (95\%CI 3.7, 4.3).

The composition of the stool samples measured by NIRA is provided in table 5 . Stool fat content decreased significantly $(\mathrm{P}<0.001)$ from $8.6 \%$ (wt/wt of stools) at enrolment to $6.8 \%$ at the second visit. There was no significant change in the other parameters. 


\begin{tabular}{|c|c|c|}
\hline & visit 1 & visit 2 \\
\hline very satisfied & 0 & 14 \\
\hline satisfied & 6 & 6 \\
\hline neutral & 3 & 0 \\
\hline dissatisfied & 10 & 0 \\
\hline very dissatisfied & 1 & 0 \\
\hline
\end{tabular}

* Number of parents in each category of Likert-type scale

Table 4: Parental satisfaction score*

\begin{tabular}{|c|c|c|c|c|}
\hline & $\begin{array}{c}\text { Normal } \\
\text { Values }\end{array}$ & Visit 1 & Visit 2 & p value * \\
\hline Fat & $7-11$ & $8.6+1.9$ & $6.8+2.1$ & $<0.001$ \\
\hline Water & $80-85$ & $78+6$ & $80+5$ & $>0.2$ \\
\hline Nitrogen & $<1.8$ & $1.4+0.3$ & $1.4+0.3$ & $>0.2$ \\
\hline Carbohydrate & $<2$ & $1.1+1.1$ & $1.2+1.4$ & $>0.2$ \\
\hline
\end{tabular}

\section{Discussion}

This case series study investigated the response to a formula type that has only been present in Europe since 2014. The formula contains goat milk proteins instead of cow milk proteins and a mixture of milk fat and vegetable oils [17,18]. Of the 23 infants initially enrolled, two withdrew due to causes considered unrelated to formula. One infant had persistent irritability and did not complete the study, but parents of the other 20 infants reported seeing improvements in infant behaviour within 3-5 days after starting the study formula. These parents also reported that acceptance of the formula was excellent and there was a high level of parental satisfaction with the formula. There was a significant reduction in fat percentage of stools and crying and a small change in stool consistency at the three weeks visit after the formula was introduced. These are indicative of an improvement in fat absorption and reduction in symptoms of constipation over the duration of the study. Stool nitrogen levels were unchanged between visits, similar to a lack of differentiation in nitrogen content of stools of breast fed and formula fed infants [12].

The results of the current study might be attributed to the unique source of fats in the study formula. Traditionally, formulas have contained substantial quantities of milk fat, but progressively they have tended to be richer in vegetable oils to supply essential polyunsaturated fatty acids [27]. The main vegetable oils used in formulas are coconut oil, corn oil, soybean oil, palm olein, palm kernel oil, palm oil, high oleic safflower oil, peanut oil, and, in Europe, low-erucic acid canola oil [27]. Fats are better absorbed from human milk than from formulas containing vegetable oils [28]. This has been attributed in part to the high proportion of palmitic acid in the middle sn-2 position in human milk compared to vegetable oils where most of palmitate resides at the outer sn-1,3 positions [14,15,29-34]. During normal digestion, triacylglycerol hydrolysis by sn-1,3 specific pancreatic lipase liberates free fatty acid in the gut [35]. Pal-mitate in the free form is rapidly converted into insoluble hydrated acid soaps at the pH of the intestine. If sufficient free calcium is present in the intestinal lumen, calcium soaps can also be formed. These soaps have very high melting points that limit their absorption and result in their recovery in stools [12,29,32,36]. Reviews and meta-analysis have concluded that the use of palm olein to match the content of palmitic acid in infant formulas to that of the human milk produced a harder stool consistency compared to formulas without palm oil [13,15]. In contrast, formulas with less palmitic acid or with more palmitic acid in sn-2 position results in improvement of fat and calcium absorption, and stool consistency [13-15, 29-34].

The fat in the formula evaluated in the present study contains 55\% of fat from goat milk and 45\% from a mixture of unmodified high oleic sun-flower, canola, and sunflower oils in a ratio of 44:30:26 to provide the appropriate fatty acid profile, including the palmitic. It contains no palm oil. The fatty acid profile and the relative positioning of the fatty acids in the triglycerides have been reported previously [18]. The total amount of palmitic acid in sn-1, 3 positions in the formula is $0.36 \mathrm{~g} / 100 \mathrm{ml}$ compared to $0.7-0.8$ $\mathrm{g} / 100 \mathrm{ml}$ in conventional formula containing vegetable oils only [37,38]. The amount of palmitic acid in sn-1, 3 in the goat milk based formula is similar to formula used in other studies to prevent the malabsorption of palmitic acid [13-15,30,31,36] and also reduced crying and symptoms of constipation [39,40]. It is likely that the use of a cow formula with a fat blend that has lower amounts of palmitic acid in sn-1,3 position would have a similar outcome to the formula used in this study.

\section{Strengths and Weaknesses of Study}

A limitation of this study is that neither the mothers nor the clinicians were blinded to the intervention and there was no parallel control group. However, there was no evidence to suggest the formula had an adverse effect on gastro-intestinal symptoms in infants that already had constipation. The improvement in stool fat content is also relatively independent of observer bias. The improvement of stool characteristics between visits, in parallel to a reduction of the number of crying episodes would suggest a 
potential benefit for wellbeing of infants with functional gastro-intestinal disorders. A follow-up randomized cross-over trial is needed to determine whether improvement can be directly attributed to the inclusion of the goat milk fat in the goat milk formula.

\section{Acknowledgement}

The authors thank Bebe Innova, El Puerto de Santa María (Cadiz, Spain) for provision of the formula and to Dairy Goat Cooperative (N.Z.) Ltd (Hamilton, New Zealand) for providing funding for sample and data analysis.

\section{Conflict of Interest}

Colin G Prosser is an employer of Dairy Goat Co-operative (NZ) Ltd. Neither Dámaso D Infante nor Ramon Tormo declares a conflict of interest.

\section{References}

1. Weaver LT, Steiner H (1984) The bowel habit of young children. Arch Dis Child 59: 649-52.

2. Tunc VT, Camurdan AD, Ilhan MN, Sahin F, Beyazova U (2008) Factors associated with defecation patterns in 0-24-month-old children. Eur J Pediatr 167: 1357-62.

3. den Hertog J, van Leengoed E, Kolk F, van den Broek L, Kramer E, et al. (2012) The defecation pattern of healthy term infants up to the age of 3 months. Arch Dis Child Fetal Neonatal Ed. 97: F465-70.

4. Iacono G, Merolla R, D’Amico D, Bonci E, Cavataio F, et al. (2005) Gastrointestinal symptoms in infancy: a population based prospective study. Dig Liver Dis 37: $432-8$.

5. Infante D, Badia X, Ariño-Armengol B, Villegas V (2008) Prevalence and dietetic management of mild gastrointestinal disorders in milk-fed infants. World J Gastroenterol 14: 248-54.

6. Baker SS, Liptak GS, Colleti RB, Croffie JM, Di Lorenzo C, et al. (1999) Constipation in infants and children: evaluation and treatment. J Pediatr Gastroenterol Nutr 29: 612-26.

7. Lucassen PL, Assendelft WJ, van Eijk JT, Gubbels JW, Douwess AC, et al. (2001) Systematic review of the occurrence of infantile colic in the community. Arch Dis Child 84: 398-403

8. Reijneveld SA, Brugman E, Hirasing RA (2001) Excessive infant crying: the impact of varying definitions. Pediatrics 108: 893-7.

9. Long T, Johnson M (2001) Living and coping with excessive infantile crying. J Adv Nursing 34: 155-162.

10. Bruning S, McMahon C (2009) The impact of infant crying on young women: A randomized controlled study. Journal of Reproductive and Infant Psychology 27: 206-20.

11. van Tilburg MA, Hyman PE, Walker L, Rouster A, Palsson OS, et al. (2015) Prevalence of functional gastrointestinal disorders in infants and toddlers. J Pediatr 166: 684-9.

12. Quinlan PT, Lockton S, Irwin J, Lucas AL (1995) The relationship between stool hardness and stool composition in breast- and formula-fed infants. J Pediatr Gastroenterol Nutr 20: 81-90.

13. Lasekan JB, Hustead DS, Masor M, Murray R (2017) Impact of palm olein in infant formulas on stool consistency and frequency: a meta-analysis of randomized clinical trials. Food Nutr Res 61: 1330104.

14. Nelson SE, Frantz JA, Ziegler EE (1998) Absorption of fat and calcium by infants fed a milk-based formula containing palm olein. J Am Coll Nutr 17: 327-32.

15. Koo WWK, Hockman EM, Dow M (2006) Palm Olein in the Fat Blend of Infant Formulas: Effect on the Intestinal Absorption of Calcium and Fat, and Bone Mineralization. J Am Coll Nutr 25: 117-22.

16. EFSA Panel on Dietetic Products, Nutrition and Allergies (NDA) (2012) Scientific Opinion on the suitability of goat milk protein as a source of protein in infant formulae and in follow-on formulae. EFSA Journal 10: 2603-21.

17. Zhou SJ, Sullivan T, Gibson RA, Lonnerdal B, Prosser CG, et al (2014) Nutritional adequacy of goat milk infant formulas for term infants: a double-blind randomised controlled trial. Br J Nutr 111: 1641-51.

18. Prosser CG, Svetashev VI, Vyssotski MV, Lowry DJ (2010) Composition and distribution of fatty acids in triglycerides from goat infant formulas with milk fat. J Dairy Sci 93: 2857-62.

19. Hyams J, Colletti R, Morais MB, Faure C, Gabriel-Martinez E, et al. (2002) Functional gastrointestinal disorders: Working group report of the First World Congress of Pediatric Gastroenterology, Hepatology, and Nutrition. J Pediatr Gastroenterol Nutr 35: S110-7.

20. Lewis SJ, Heaton KW (1997) Stool form scale as a useful guide to intestinal transit time. Scand J Gastroenterol 32: 920-4.

21. Benini L, Caliari S, Guidi BC, Bretegani MT, Castelani G, et al. (1989) Near infrared spectroscopy for fecal fat measurement: comparison with conventional gravimetric and titrimetric methods. Gut 30: 1344-7.

22. Picarelli A, Greco M, Giovambattista F, Ramazzotti A, Cedrone C, et al. (1995) Quantitative determination of faecal fat, nitrogen and water by means of a spectrophotometric technique: near infrared reflectance analysis (NIRA). Assessment of its accuracy and reproducibility compared with chemical methods. Clin Chim Acta 234: 147-56.

23. Neumeister V, Henker J, Kaltenborn G, Sprössig C, Jaross W (1997) Simultaneous determination of fecal fat, nitrogen, and water by near-infrared reflectance spectroscopy. J Pediatr Gastroenterol Nutr 25: 388-93.

24. Neucker AV, Bijleveld CM, Wolthers BG, Swaaneburg JC, Kester AD, et al. (2002) Comparison of near infrared reflectance analysis of fecal fat, nitrogen and water with conventional methods, and fecal energy content. Clin Biochem 35: 29-33.

25. Tormo R, Infante D (2003) Valoración no invasiva de la administración en recién nacidos y lactantes afectados por cólicos del lactante de una fórmula de inicio y otra de adicionada. Acta Pediatr Esp 61: 601-11.

26. Rivero-Marcotegui A, Olivera-Olmedo JE, Valverde-Visus FS, Palacios-Sarrasqueta M, Grijalva-Uche A, et al. (1998) Water, fat, nitrogen, and sugar content in stools: reference intervals in children. Clin Chem 44: 1540-4.

27. Delplanque B, Gibson R, Koletzko B, Lapillonne A, Strandvik B (2015) Lipid Quality in Infant Nutrition: Current Knowledge and Future Opportunities. J Pediatr Gastroenterol Nutr 61: 8-17. 
28. Fomon SJ, Ziegler EE, Thomas LN, Jensen RL, Filer LJ (1970) Excretion of fat by normal full term infants fed various milks and formulas. Am J Clin Nutr 23: 1299-313.

29. López-López A, Castellote-Bargalló AI, Campoy-Folgoso C, Rivero-Urgël M, Tormo-Carnicé R, et al. (2001) The influence of dietary palmitic acid triacylgyceride position on the fatty acid, calcium and magnesium contents of at term newborn faeces. Early Hum Dev 65: S83-94.

30. Bar-Yoseph F, Lifshitz Y, Cohen T, Malard P, Xu C (2016) SN2-palmitate reduces fatty acid excretion in Chinese formula-fed infants. J Pediatr Gastroenterol Nutr 62: 341-7.

31. Carnielli VP, Luijendijk IHT, van Goudoever JB, Sulkers EJ, Boerlage AA, et al. (1996) Structural position and amount of palmitic acid in infant formulas: effects on fat, fatty acid, and mineral balance. J Pediatr Gastroenterol Nutr 23: 554-60.

32. Carnielli VP, Luijendijk IHT, van Goudoever JB, Sulkers EJ, Boerlage AA, et al. (1995) Feeding premature newborn infants palmitic acid in amounts and stereoisomeric position similar to that of human milk: Effects on fat and mineral balance. Am J Clin Nutr 61: 1037-42.

33. Innis SM, Dyer R, Nelson CM (1994) Evidence that palmitic acid is absorbed as sn-2 monoacylglycerol from human milk by breast-fed infants. Lipids 29: $541-5$. 34. Filer LJ, Mattson FH, Fomon SJ (1969) Triglyceride configuracion and fat absorption by the human infant. J Nutr 99: 293-8.

35. Bernback S, Blackberg L, Hernell O (1990) The complete digestion of human milk triacylglycerol in vitro requires gastric lipase, pancreatic colipase-dependent lipase, and bile salt-stimulated lipase. J Clin Invest 85: 1221-6.

36. Nowacki J, Lee H-C, Lien R, Cheng S-W, Li S-T, et al. (2014) Stool fatty acid soaps, stool consistency and gastrointestinal tolerance in term infants fed infant formulas containing high sn-2 palmitate with or without oligosaccharides: a double-blind randomized clinical trial. Nutr J 13 : 105.

37. Straarup EM, Lauritzen L, Faerk J, Hoy C-E, Michaelsen KF (2006) The Stereospecific Triacylglycerol Structures and Fatty Acid Profiles of Human Milk and Infant Formulas. J Pediatr Gastroenterol Nutr 42: 293-9.

38. López-López A, López-Sabater MC, Campoy-Folgoso C, M Rivero-Urgell, Castellote-Bargalló AI (2002) Fatty acid and sn-2 fatty acid composition in human milk from Granada (Spain) and in infant formulas. Eur J Clin Nutr 56: 1242-54

39. Bongers MEJ, de Lorijin F, Reitsma JB, Groeneweg M, Taminiau JAJM, et al. (2007) The clinical effect of a new infant formula in term infants with constipation: a double-blind, randomized cross-over trial. Nutr J 6: 8 .

40. Litmanovitz I, Bar-Yoseph F, Lifshitz Y, Davidson K, Eliakim A, et al. (2014) Reduced crying in term infants fed high beta-palmitate formula: a double-blind randomized clinical trial. BMC Pediatr 14: 152

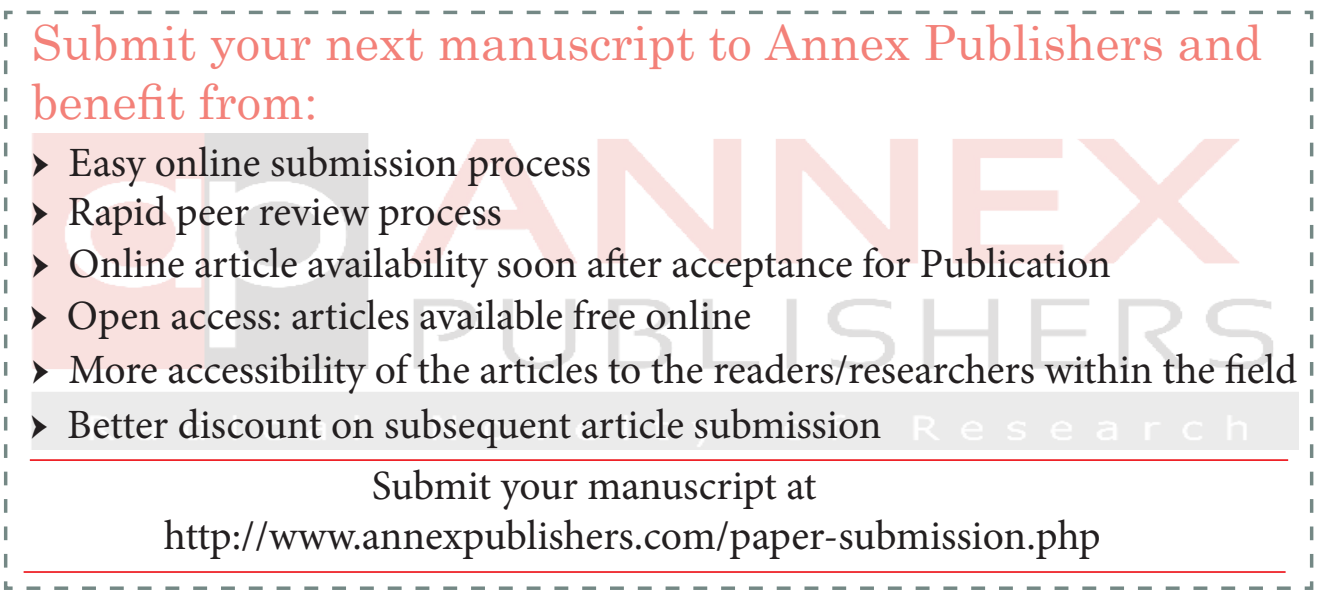

